\title{
Mental Sub-Normality: Mainstreaming Children with Disabilities. The Challenges of the Counseling Profession
}

\author{
Effiom, Bassey Ekeng ${ }^{1^{*}}$ and Stella Bassey Esuabana ${ }^{1}$ \\ ${ }^{1}$ Department of Guidance and Counseling, University of Calabar, Calabar, Nigeria.
}

Authors' contributions

This work was carried out in collaboration between both authors. Author EBE designed the study. Authors EBE and SBE performed the statistical analysis. Author EBE wrote the protocol and wrote the first draft of the manuscript. Authors EBE and SBE managed the analyses of the study. Author SBE managed the literature searches. Both authors read and approved the final manuscript.

Article Information

DOI: $10.9734 / A R R B / 2020 / v 35 i 1230325$

(1) Dr.Paola Angelini, University of Perugia, Italy.

Reviewers:

(1) Ibrahim El-Zraigat, The University of Jordan, Jordan. (2) Elías Ernesto Aguirre Siancas, Universidad Nacional Mayor de San Marcos, Perú. Complete Peer review History: http://www.sdiarticle4.com/review-history/56928

Review Article

Received 20 October 2020

Accepted 26 December 2020

Published 31 December 2020

\begin{abstract}
This paper takes a critical look at mental sub normality, mainstreaming children with disabilities and the challenges of the counselling profession. Its use children that need special education, the blind, epileptic, partial deaf. Since they have rein-force stigmation. Inclusive approach, re-affirmation, care and integration, confidence building institutionalized in school and family life. Using guidance and counselling as the best approach to adjust the different maladaptive behavior of children in school. This works seem to view sub Normality as classify within range although adequacy of social adaptation is taken into account. As it may include brighter even cluster student, this children may be term educational sub normal. They may have weak intellectual capacity, some educational authorities have special school for them. But else where they are accumulated in normal school example Nigerian.

Sub mentality suffer discouragement, contempt and neglect from early age. Emotionally and social growth they cannot respond as adequately to the environment as can normal children, they are likely to feel isolated and to be excluded from social activities from early childhood. Therefore, counsellor must experience sub normality by getting involve and clarify their feeling towards children with disabilities.
\end{abstract}


Keywords: Mentality; sub normality; mainstreaming; disabilities; children; counselling.

\section{INTRODUCTION}

Childhood learning maybe more influential then learning physiological behavior involves in dullness \& backwardness, heart beat, muscle tension and brain waves. The class of children that need special education treatment are: The blind, the partial sighted, deaf, partial deaf, the delicate. Others are educational sub-normal, the epileptic, the maladjusted, the physically handicapped and those with speech defects. This condition occurs in a normal family [1].

Sub-normality is complex, uncertain, quite confusing. Rather, segregated children with disabilities, have re-enforce stigmatization inclusive approach through mainstreaming are more institutionalized. Disabilities children should be care and integrated through re-affirmation, confidence building understanding and accepted alongside with disability education.

Counseling therefore is a service that is both preventive and corrective especially with mental sub-normality and treatment strategies for mental disorder.

Davidoff [2]. Cites three therapeutic orientations considered

Fundamental:
a) Psychoanalysis behavior
b) Humanistic
c) Existential.

The three restored healthy functions though differ on conception of maladaptive behaviour and primary procedure.

The education of all mentally handicapped children is both the responsibility of government and families noting that this condition tend to occur in families [3].

Sub mental in some instance arise as a result of large family arising from neglect, inadequate food over look of early infection, the mother maybe promiscuous and the father maybe a drunkard, this is frequently with juvenile delinquency - so it is important that sub normality should be detected at early stage and be given attention example, reading, writing and simple number work or an intellectual stimulating atmosphere and opportunity to develop good social and emotional adjustment. Sub normal children grow up to self-respecting and supporting adult. The student that is sub normal should be always reported to a guidance counsellor in the school, sub normal student sometimes come from family with lower social-economic status [4].

\section{CAUSE OF MENTAL SUB-NORMALITY}

Birth injuries, early infection, metabolic disorder, severe emotional disturbance, poor up bringing, poor quality of neural mechanism which the child is born and cause by poor environmental stimulation[5].

\subsection{Parental Development Disorder}

At birth children have different problem associated with pregnancy and the different environment condition viewing the social, physical economic structure of parent, and the Educational level, and proximity to health and medical facilities. Therefore, mal-function in foetus during growth within the mother uterus can bring about injuries, body temperature conditions, chemical conditions, temperature conditions, interference with oxygen supply and nutrition. Under development in the size of the brain in micro cephalic [5].

Although, such disorder is sometimes due to genetic causes, toxic substance produced in a mother if the blood is negative and she is carrying a foetus whose blood is positive. This poison when reach the foetus may cause damage to the blood, liver, brain, at birth such children may have anemia, jaundice, or paralysis etc.

\subsection{Infectious Diseases}

Children suffer different early birth disease which causes different malfunctions and impair their health and circumstance of their birth such disease as measles, scarlet fever, mumps, whooping cough etc. this may cause retardation in learning process example to speak, walk and intelligent development [6].

metabolic disorder may arise as a result mental deficiency e.g amaurotic, idiocy, gargoylism and phenylketonuria.

\subsection{Chromosome Imbalance is a Drastic Mental Deficiency}

This can be referred to mongolism resulting to short growth, slanting eyes, depressed nose 
bridge, dry lips, open mouth, enlarged and fissured tongue, flat facial features.

Consequently, when the ovum is formed after fertilization the body cells of the embryo contain an unusual numbers of chromosomes leading to abnormal development [7].

\subsection{Birth Injuries}

Cerebral palsy is a disorganization of the motor control system as a result of damage to the central nervous system, birth injuries can be viewed as a complication either before or after birth process.

Mainstreaming disabilities in children building self-confidence and informing about wholeness and ability with strong disposition in addition with strong teacher advocacy, guidance and counseling of disabilities is to equip the school population with forth right attitude, technique and skill of acceptance and integration of disable children (Govig 1989) as he or she prevails over the area of difficult in life. He has selfmanagement affirmation and resources and selfunderstanding in area of great strength [8].

\section{THE CHALLENGES OF THE COUNSELING PROFESSION}

Social development involves the training the child receives on his interpersonal life and how he relates socially with his peers and others. The child is observed on how he resolves small conflicts; whether he cooperates, leads, fellows or play along when in a group, how he responds to simple training in manners and independence. Specifically, the teachers should study the child's social development through his family type i.e. living together or separated. father's occupation, wealth of the family, attitude of the parent to child and vice-versa, the peer group he plays with, his neighborhood, his moral standard and the type of people he appreciate or copies as models.

The mental health is important for elimination of tension of the client, such traits, like anxiety, hostility, depression, feeling of inferiority, inadequacy, unhappiness and other emotional symptoms such be put under conscious control which involve internal and external environment [9].

Counseling help the client/person with subnormality towards overcoming obstacles to their personal growth and development wherever the maybe encountered. The counselling service provide to children with disabilities are significantly outside the average range of general counselling. Many area of the counselling profession in primary school has fallen short, with a luck of understanding and appreciation (e.g., attitude, values, and belief), a limited repertoire of skills. When school counselor do not provide service or develop programs to accommodates the needs of children with disabilities, they deny these student of their expertise and themselves of the enrichment that come with working with children with disabilities who are challenging, deserving and responsive [10]. There are a number of additional factors that are contributing to the low professional visibility of school counselors; lack of well defined school counselor's roles, goals and job description too many administration routine assignments and too high counselor - student ratio that don't allow school counselors to use their special skills. However, all student refers to those who are average, gifted and talented. Low achieving and to those with handicaps and disabilities; those in all ethnic, and cultural, groups; those who speak Turkish as a second language; migrants; boys and girls; and any other "special student" in the school. this principal indicates that all students, including children with disabilities, should have equal access to counselors, the guidance curriculum, counselling resources, and all other direct and indirect services. Children with disabilities will experiences some of the following problems throughout their school age years. They may be subjected to a multitude of obstacles and barriers. In some cases, these children experience more than their normal share of frustration and difficulty in attempting to resolve the issue that are encounter with daily living activities. It is not uncommon for children with disabilities to experiences chronic hopelessness as a result of anxiety and depression. Sometimes they have access and performance problem in schools, which could or would not be related to the disability. Also, they show delayed in development of self - concept that can influence one's sense of self - worth, and viewing one's self as dumb, damages, weak, and vulnerable. Counselling professionals historically, have had limited contact with this population for a variety of reasons. Some counselors lack confidence and training to serve these groups. Some are uncomfortable around peoples with disabilities. Others have incorrect information about or prejudices towards those with exceptional needs in addiction, because 
services to children. Although children with disabilities are extremely heterogeneous group of diverse leaners, each with unique learning strengths and needs many of the graduates counselor education programs have not provided prospective school counselor with adequate training for the development and provision of services or how to professionally interact with children who have disabilities, which includes physical behavior, emotional and mental disabilities. In addition, limited preparation is provided in the area of cooperation and collaborative effort in working with other specialist and professionals to provide children with disabilities a more comprehensive developmental holistic approach to services [11].

\section{COUNSELLING CHILDREN WITH SUB - NORMALITY}

Counselling Children with sub-normalities are often misunderstood and frequently less served by the counselling profession, these children need services just as much as other children. In addition, all counselors have a professional and ethical responsibility to facilitate conditions that promote full potential for all individuals, including exceptional groups. As knowledge and experience are obtained for this population, counselor can serve children and their families more fully as intend by legal and professional guidelines. Most counselor, however, do have many of the skill needed to work with these children and their families, such as communication strategies, a background in human, and experience with an array of therapeutic analysis. Moreover, a proactive approach to the role of techniques, a focus on relationship-building, a desire to operationalize equal opportunities policies, an inclusive approach to initial assessment, flexibility and creative approach to counseling, continuing professional training and awareness raising can be important facts in counselling processes [12]. From a counseling perspective, these students, regardless of their specific handicap, present similar characteristics that preclude using traditional counselling methods. Inherently all of these student are believed to experience developmental delays that may impair one or more of their learning channels and may range from mild to severe. Individuals may exhibit inappropriate behavior relative to their chronological age often are socially isolated. A poor self-concept is another quality found in this target population. Students may also lack adequate expressive language, are often disorganized in their thought processes, and usually have considerable difficulty with time management skills. Keeping these factors in mind, school counselors should be encouraged to do more in-depth research and preparation on specific disabilities, with strategies an interventions to assist the scope and direction of intervention that are effective when developing program and providing services to children with disabilities. A number of empirical studies have verified the positive effect of group counselling intervention. Students have shown significant increase in academic persistence and achievement, school attendance, classroom behaviors, self-esteem, self-concept, and their attitudes towards school and others. This degree held for special population groups, including lowachievement students, disruptive student's, learning-disable student and gifted students. As school counselors prepare to provide counselling service, it is important not to generalize across sub-normality, putting children and adolescent with disabilities at risk. This children and adolescents vary just as individual in any other group. Intervention may need to be more handson in the approach to the problem resolution as well as culturally sensitive. External issues, which are problems outside the child, may need to be addressed because of the direct or indirect implication. In addition, it is critical that school counselors have knowledge of the laws and understand the right of children with subnormality [13]. All of this issues challenges counseling professionals to be creative. Counselor attend to instructional practices, staff, student interactions, and other environmental interventions have a substantial impact on students' educational and personal development. The initial stage of counselling requires the manipulating of several components in the counselling environment.

Distraction in the environment should be kept to minimum or eliminated. Tasks should be structured and followed consistently. Multisensory approaches including auditory, visual, tactile, and kinesthetic, should be used by counselors while presenting activities to the students. All of the components are designed to keep student confusion and frustration to minimum and still allow the participants to function in a well - controlled environment using multisensory approach to promote understanding. The ability to communicate concretely is vital for success with handicapped students. Verbal generalities should be avoided. 
Short, concise, explicit sentences should be employed. These guidelines will enable student to understand specific concept and terminology used to by the counselor so that they will be able to concentrate on learning. Frequent and consistent repetitions are needed during the counselling session. A review of previous meetings and their objectives should be told what to expert at each session [14]. A summary of the activity should be presented stressing the important areas for students clients to remember. Repetition allow students to absorb each session and understand the continuity of the presentations. There is widespread consensus concerning the desired nature and scope of school counselling for children with disabilities which includes interventions to increase awareness, acceptance, and appreciate of cultural diversities. In addition, counselors attend to school policies and procedures, instructional practices, staff student interactions, and other environmental factors that may impede development of the student because, school counselling interventions have a substantial impact on student because, school counselling interventions have a substantial impact on students educational and personal development. Moreover, individual and small-group counselling, classroom guidance, and consultation activities seem to contribute directly to student success in the classroom and beyond, and school counselor such the majority of their time performing intervention. It is in the spirit of empowering the school counselor should grain their credibility, assert their significance, and make their own unique place in the school counselling is postulated.

To become proactive, it is high time that counselors use a balanced approach to counselling and heed baker's [14,15] admonition: counselor in the twenty-first century must be able to provide prevention service that meet and enhance developmental needs and treatment service when interventions are needed. Counselors will need to be flexible in reacting to differing client demands and be proactive in providing services that enhance person development and coping skills. this approach requires school counselors to shift from a primarily responsive service orientation to school counseling partnerships that are proactive and developmental. Proactive approach is an advocacy approach to promote and support student's interest. When a school is not responsible to the needs of students or there are some school practices that are detrimental to the interests of students, a counselor might have to make a difficult choice either to meet the need students or the demands of the institution [15].

Proactive counselor serve as strong advocates of students when they have to face such matters as "confidentiality, injustice to student, inappropriate curricula, incompetent teachers, and unresponsive administrators" [16,17]. In their advocacy role, school counselors can collaborate with teachers to maximize potential of their students through information about different learning styles, motivational strategies, and new pedagogical approaches. Student problems require enormous amount of time, networking with other is not a matter of luxury but a necessity. According to $[18,19]$, a counselor can build a large support group by developing a systematic, long-term liaison with number of diverse groups within and outside the school. within the school, student trained as peer counselors can effectively present topics such as self-esteem, peer pressure, time management, etc. to lower grade students. Similarly teachers trained by counselors could provide some group guidance activities in interpersonal skills, developing friendships, lifestyle decisions, developing self- discipline, and leadership skills. School counselors function at the forefront level in a manner that enhance teacher contribution in the proactive approach process [20].

\section{CONCLUSION}

Counselor should prepare themselves to serve group in several ways. As a first step, they must clarify their feelings and attitudes about working with children who are sub normal.

Pity, low expectation, repulsion to physical abnormalities, misinformation, and other biases can preclude effective counselling. Correct information and direct experience can facilitate accurate awareness and acceptance of those groups. In addition, counselors must obtain knowledge and training for working with specific group with exceptional needs. They can obtain this knowledge and training for working with specific groups with exceptional needs. They can obtain this knowledge through, counselling workshops, consultation, supervision, current therapeutic literature, and community resources etc. 


\section{DISCLAIMER}

The products used for this research are commonly and predominantly use products in our area of research and country. There is absolutely no conflict of interest between the authors and producers of the products because we do not intend to use these products as an avenue for any litigation but for the advancement of knowledge. Also, the research was not funded by the producing company rather it was funded by personal efforts of the authors.

\section{COMPETING INTERESTS}

Authors have declared that no competing interests exist.

\section{REFERENCES}

1. Baker SB. School counselling for the twenty-first century. New York: Macmillan publishing company; 1992.

2. Davidoff LL. Introduction to psychology. New York: Mc Graw Hill; 1987.

3. Govig SD. Strong at the broken places: person with disabilities and the church. Louisville: West Minister/ John Knox Press's; 1989.

4. Aubrey RF. Historical Development of Guidance \& Counselling and implication for the future - Personnel \& Guidance Journal. 1977;55(1):288295.

5. Calicchia J, Graham L. Assessing the relationship between spirituality, life stressors, and social resources: Buffers of stress in graduate students. North American Journal of Psychology. 2006;8: 307-320.

6. Corrigan P. How stigma interferes with mental health care. American Psychologist. 2004;59(7):614625.

7. Corrigan PW, Watson AC, Barr L. The selfstigma of mental illness: Implications for self-esteem and self-efficacy. Journal of Social and Clinical Psychology. 2006; 25(9):875-884.

8. Dearing RL, Maddux JE, Tangney JP. Predictors of psychological help seeking in clinical and counseling psychology graduate students. Professional Psychology: Research and Practice. 2005; 36(3):323-329.

9. Goldberstein E, Eisenberg D, Gollust S. Perceived stigma and mental health care seeking. Psychiatric Services. 2008;59: 392-399.

10. Holmes RP, Corrigan PW, Williams $\mathrm{P}$, Canar J, Kubiak MA. Changing attitudes about schizophrenia. Schizophrenia Bulletin. 1999;25:447-456.

11. Horsfall J, Cleary M, Hunt G. Stigma in mental health: Clients and professionals. Issues in Mental Health Nursing. 2010;31: 450-455.

12. Hugo M. Mental health professionals' attitudes towards people who have experienced a mental health disorder. Journal of Psychiatric and Mental Health Nursing. 2001;8:419-425.

13. Martin J. Stigma and student mental health in higher-education. Higher Education Research \& Development. 2010;29(3): 259-274.

14. Overton S, Medina S. The stigma of mental illness. Journal of Counseling \& Development. 2008;86:143-149.

15. Penn DL, Martin J. The stigma of severe mental illness: Some potential solutions to a recalcitrant problem. Psychiatric Quarterly. 1998;69:235-247.

16. Rogers-Sirin L. Segmented assimilation and attitudes toward psychotherapy: A moderated mediation analysis. Journal of Counseling Psychology. 2013;60(3):329339.

17. Rønnestad $\mathrm{MH}$, Skovholt TM. The journey of the counselor and therapist: Research findings and perspective on professional development. Journal of Career Development. 2003;26(8):960981.

18. Smith AL, Cashwell CS. Stigma and mental illness: Investigating attitudes of mental health and non-mentalhealth professionals and trainees. Journal of Humanistic Counseling, Education and Development. 2010;49: 189-202.

19. Vogel DL, Bitman RL, Hammer JH, Wade NG. Is stigma internalized? The longitudinal impact of public stigma on self stigma. Journal of Counseling Psychology. 2013;60(2):311-316. 
20. Vogel DL, Heimerdinger-Edwards SR, Hammer JH, Hubbard A. Boys don't cry: Examination of the links between masculine norms and help seeking attitudes for men from diverse cultural backgrounds. Journal of Counseling Psychology. 2011;58:368-382.

(c) 2020 Ekeng and Esuabana; This is an Open Access article distributed under the terms of the Creative Commons Attribution License (http://creativecommons.org/licenses/by/4.0), which permits unrestricted use, distribution, and reproduction in any medium, provided the original work is properly cited.

Peer-review history:

The peer review history for this paper can be accessed here: http://www.sdiarticle4.com/review-history/56928 